\title{
Study on the role of team spirit in university in the construction of class collective
}

\author{
Zhu Yawei ${ }^{\mathrm{a}}$, Qi Yuanjun ${ }^{\mathrm{b}}$ \\ Northeast Petroleum University, China \\ azhuyawei@nepu.edu.cn,bdydqyqyj@126.com,
}

Keywords: Colleges, class, team

\begin{abstract}
Class is the main carrier of student's growth, as the basic organization of the students. In the construction of class of the new period, we should integrate the team consciousness gradually into traditional concept of collectivism on the basis of learning organization of the five elements, leading college students to learn , think and create independently, to achieve common progress of team and individual.
\end{abstract}

\section{Introduction}

Class is the basic organization of college students, and is an important environment and the basic carrier of university student .Whether the functions of the class are played fully, directly affect the students' study and life[1].A harmony and stability class with a same goal , is helpful to guide and promote college students to set up the correct world outlook, the outlook on life and values, cultivate good habits, fully excavate intelligence, talent and creativity, sets up the broad ideal, enhance the collective ideas and cooperation spirit, achieve common progress of individual and collective.

\section{The problems of the construction of the class in the university}

The class in the college is usually based on the professional and grades, under the regulations and requirements of the traditional academic year system, the students of same class are in accordance with the same schedule, and participate in collective activities. With the credit system in university promoting and the rising of new media organizations in the same way of life, all kinds of organizations with the same way of life, a common hobbies and interests, let the students to form a new group.

The caucus organization. College students' party branch and the youth corps committee, has its distinct political and the specific content, is the main carrier of ideological and political education in colleges and universities, and directly affects the formation of college students' values. Communists and cadres among the students with strong directivity, and exemplary role, to influence and drive the ordinary students. In the special period and a major event occurs, the role of caucus organizations is particularly important.

Student organizations and all kinds of interest groups. Student organizations and all kinds of amateur groups develop because of the expansion of the variety and quantity of college students' interest, The specialty and interest of college students are more extensive, common interests led to a group. The class members are all over the entire school, students get closer in the spontaneous organization's activities, and enhance feelings.

The dormitory. In addition to class time, more and more college students like staying in the dormitory, combining with the school hardware facilities is limited, the activity field is less, the dormitory has become the main place of college students' daily life. Students between the different class but with the relation between the dormitory members are more closely than the class from different dormitory. Network virtual organization. The rising of new media, changed the traditional mode of communicating, from interactions and communications to after school activities, network has brought about great changes to the lives of college students. QQ, micro letter, BBS, game organization let 
college students be a team, in and out for freedom, through a cable, and the member structure change quickly.

The existence of these organizations, to a certain extent, makes the class function and role face enormous challenges, the concept of class in the students heart gradually fade out. But whether affected by the credit system or growing new campus organization, the traditional class with a long-term, stability, and centripetal force will take precedence over any other organization, it is still a organization where college student mainly learn and live. Therefore, we should actively explore and adapt to the new situation of the construction of the higher education method.

\section{The class collective spirit and team spirit}

In the construction of higher education we should firstly emphasize the collective concept. Collectivism is one of the contents of the worldview of the proletariat, it is the principle of regulating personal interests and collective interests. Refers to all the words and deeds in accordance with collective interests of the proletariat and the masses of the people as the basic starting point of thought. Collectivism is the core of communist morality, it is an important symbol of socialist spiritual civilization. Collective promote personal growth strongly. personal effort lead collective progress. Nowadays, college students are more willing to accept the new team. Team spirit is the collective idea of China, the wisdom of teams of two internationally renowned author Jon r. Bach, Douglas k. Smith, stresses the concept of the team: the team is not refers to any group to work together. Team work represents a series of positive responses to encourage listening, others view, provide support to others and respect others interest and achievement values. A team must have a mutual understanding of the behavior, the same goal concepts and values of convergence, to form a collective consciousness from psychological, thought, behavior etc.. First of all, members of a team is the most basic constituents of a team, members are selected with reasonable configuration; Second, the task between team members is different, have their own responsible area; Again, team management process, there is a difference between treatment of each member and this make each member's personality can be fully played and continue to develop. The team is based on respect for the personal interest and achievements, the team and the internal settings, select different talents, training and recognition, so that every member can fully display and development. Team spirit is the core of collaboration, do not require members to sacrifice themselves to accomplish the same thing, but for the use of the self to do one thing, to realize the self achievement better, get common contribution depends on the individual members of the collective achievement. Team spirit realm is cohesion, of all the members of the centripetal force and cohesive force, is an important symbol of a loose collection of individuals to the team, this team member consciousness from the inner power and consensus values.

A class is a team. From the perspective of management, team building, first of all, determine the common goal. Clear common goal of the construction of the class, can guide students to establish correct personal goals, make personal goals and the collective goal, ensure that the development of the individual do not deviate from the correct orbit; which can lead to each class member around common goals in class activities, and cooperate with each other in their activities, coordinate with each other, enhance class cohesion and centripetal force. In the explicit goal, class construction should adhere to class a common goal as the reference, based on student personal goals, by good for beauty, intelligence and physique, "four good" as the standard; After class construction goals established, should pay special attention to the implementation in earnest, especially to establish an effective assessment and incentive mechanism, arouse the enthusiasm of each member of the class, initiative and creativity, to ensure the goals.

\section{Team organization based on the five elements of the learning}

Learning Organization, The American scholar Peter Senge in The "Fifth Discipline", The author puts forward The management idea, The Learning Organization includes five elements[2], Building 
Shared Vision: Vision can condensed member's willpower, through group consensus, efforts in the same direction, The individual also dedicated, struggle for organizational goals. b, Team Learning: the Team wisdom should be greater than the average of the individual wisdom, to make the right decisions, through thinking and analysis of collective, finding out personal weaknesses, strengthen the Team centripetal force. c, Improve getting Models : organization obstacles, more from the old thinking of the individual, such as stubborn, selfish departmentalism, only through team learning and benchmarking study, can change the Mental model, innovation. d, self beyond (Personal Mastery) : individual willing to work, professional specialization job skills, there's a "creative tension" between individual and vision, it is the source of self-transcendence. e, System Thinking: we should gather information and grasp of the whole event, to avoid missing the forest for the trees and develop The overall thinking ability, see the nature of the problem clearly.

\subsection{The constitute of the class team}

Learning organization five elements provide effective guidance to the team construction of college class construction, based on the guidance, according to the students in school during the group to learn life: adapt to the university life, professional knowledge learning, campus life, personal growth and development, interest all aspects of training, graduate employment, psychological health education so, university students in the school, the main scope of activities will not be limited to passive classes, but in a professional setting and interest of students as the abscissa axis, to the age and the tasks for the vertical axis

1. Determining the class affairs management team, ensure daily work. It should be a democratic way to improve the class organization, democratic elections and manage the class cadre; Emphasizes the host status of each member of the class, encourage everyone to participate in class affairs; Building up the idea of people-oriented, respecting the rights of students, on the basis of widely accepted by the members of the class rules.

2. Giving priority to student party members to set up the ideological and political education team, driving the activist to join the party and league members. Ideological and political work must take discussion, inspire, explanation, demonstration, attract persuade method, such as inspiring guide students to think independently, self education, ability makes the requirement of the ideological and political education to young students conscious action. Pushing forward the innovation of counselors, teachers teaching, management and service mode, the equality of the college students pay more attention to communication, communicating adequately. Cultivating harmonious class culture. Any team or group in order to achieve harmony, is inseparable from the support of harmonious culture. Good class culture can edify the class member's sentiment, improve class members thought, help to increase the cohesion of class. Cultivate harmonious class culture, we should actively guide and inspire consciously, discussing the principle of participation, self construction, and pay special attention to several links such: strengthen the ideological education, often make the class members to establish lofty ideals and firm faith, to cultivate a strong collective sense of honor, forming a great interest in learning and research; Formed by mutual understanding, mutual respect, mutual care for the important characteristics of a harmonious interpersonal relationship, timely discover and solve the class differences in understanding between members, psychological barriers, ideological contradictions, conflicts in action.

3. Building student development team by considering the student community, to increase the students' sense of belonging. Rich and colorful cultural activities, cultivating class members of the team spirit, team spirit, so that students can realize the importance of cooperation for success; With the continuous development of college student associations, the management and operation mechanism has been normalized. Community education and service function is increasingly prominent, the obvious role in promoting the construction of harmonious campus. First, the health of the college society activities carried out, which is beneficial to promote college students' all-round development. College students community as the supplement and extension to the classroom education of colleges and universities, because of its specialty and cross, activity of practicality, the organization's social 
and has the function of education and practice for the improvement of students' comprehensive quality has provided a broad stage, and all the students on the basis of voluntary formation of all kinds of social organizations, widen our sight and is conducive to college students increase knowledge, cultivating ability, edify sentiment, promote their all-round development. Second, community college students on students' psychological mature and perfect personality. Again, the health of the college society activities carried out, which is beneficial to the cultivation of college students' social practice ability. In the new era of college students, from school to school, book knowledge learned a lot, biggest weakness is the social practice ability is poor, the student to the society after graduation, poor adaptability, adapt to the cycle is long, is not conducive to the cultivation of innovative ability and pioneering talents.

4. By professional learning, establishing professional knowledge practice team. With the appearance of new scientific and technological achievements, undergraduate course applied talents training target must be researched by market, continuously be updated and adjusted. At present, the undergraduate course in our country is widespread applied talents training "heavy theory, light practice" .when students finish school, it would take a long time of training to truly meet the needs of industrial production. This will increase the cost of unit of choose and employ persons human resources development. For students to master the solid basic theoretical knowledge is important, but if we don't improve the practice ability, the function of the theoretical knowledge cannot be effectively play, finally can only be an armchair strategist. Therefore, combined with professional knowledge, let the students during the period of school can be carried out in accordance with the industry requirements and practical learning, integrates the knowledge of the industry expert experience in parallel to the learning process, make with them after graduation can be the fastest to adapt to the working environment, although can greatly increase the complexity of the coordination between industry and education management and effort, but can realize the talent cultivation and use of "seamless connection".[3] Pay attention to the students' innovative spirit and innovative thinking ability, inspire students to pursue truth, advocate science, enterprising enthusiasm. Professional knowledge practice team, with strong learning ability of students in organization and management, seek professional class teacher's guidance, students are encouraged to apply this discipline and interdisciplinary knowledge, hands-on learning to products, processes and systems design and implementation; So that the students can learn basic skills and interpersonal skills; So that the students can easily participate in group activities, to communicate with others; To stimulate students' interests and potential, to cultivate the students' sense of team spirit and innovation for the purpose of building suitable for different level students cultivation practice education content system.

In each team forming, emphasized with the overall design conception to guide team, with practical effect to improve the operation process, with a shared vision to promote mutual learning, self-improvement to trigger system thinking.[4] Collective construction development center on the main aspects of personal growth.

\subsection{The counselor, the class cadre and students play their principal role}

In the new class structure, party organizations as the guide of the student collective, exemplary role of party members and cadres are important, into the classes, group activities of the organization will be into the general students. Class cadre's position and responsibilities also changed, according to the needs of every main task and team, the class cadre role as guide and organization, guide and stimulate the development of all students. Set is no longer a static class cadres, but according to the study emphasis of every school year according to the concept of merit were assessed and introducing competition consciousness and the concept of team work, make the most suitable on the most appropriate post service for students. Working class and the class cadre have clear goals, make ordinary students as the main body of learning and activities. [5] New class structure is appropriate from junior to pilot, according to the class to improve the main task of the various stages of development, to perfect the related system and practice development. Let the student down-to-earth, keep pace with The Times, teamwork, innovation, ultimate sign before graduation student's 
comprehensive ability, the condition of psychological health, group awareness enhancement, individual employment or business smoothly.

Put the team spirit into college class construction, to make students management themselves, and let students choose partners in study and life, to make plan and form a common vision, improve the ability in learning and innovation.

\section{Acknowledgements}

This work was financially supported by the Humanities and Social Science Research Projects in Hei longjiang Province Education Department (Special University Student Work) (1253xs321).

\section{References}

[1] Wei Dajie ,Xu Ziran: Thoughts on Strengthening Universities Class Construction: Humanities Forum, p226.

[2] Peter M. Senge: The Fifth Discipline, (The Art and Practice of the Learning Organization,2009).

[3] He Runfang, He Yimin. Class training and the formation of the wind, China Science and Education Expo, Vol.1 (2005), p.25

[4] Zhang Fuji,Li Jiyan, Ideological and Political Education, Sichuan Education Press,p.64

[5] Liu Ganxin, Luo Qiang, The role of teamwork in college counselor Brand Innovation Team, Journal of Beijing University of Aeronautics and Astronautics( Social Sciences Edition)Vol.25 No.1,January, 2012 